\title{
Postoperative pneumonia in geriatric patients with a hip fracture: incidence, risk factors and a predictive nomogram
}

\section{Xin Zhang}

Changhai hospital affiliated to the Second Military Medical University

\section{Xu-zhou Duan}

Changhai hospital affiliated to the Second Military Medical University

Da-ke Tong

Changhai hospital affiliated to the Second Military Medical University

Fang Ji ( $\sigma$ jifangdirector@sina.com )

Changhai Hospital

\section{Kai-hang Xu}

Changhai hospital affiliated to the Second Military Medical University

\section{Rong-zhi He}

Changhai hospital affiliated to the Second Military Medical University

\section{Research}

Keywords: hip fracture, geriatric, postoperative pneumonia, nomogram

Posted Date: July 16th, 2020

DOI: https://doi.org/10.21203/rs.3.rs-35763/v1

License: () (1) This work is licensed under a Creative Commons Attribution 4.0 International License. Read Full License 


\section{Abstract}

Background : To evaluate the incidence and risk factors of postoperative pneumonia (POP) in geriatric patients with a hip fracture after surgery, to design a predictive nomogram and to validate the accuracy of the nomogram.

Methods : We retrospectively studied 1285 surgical-treated geriatric patients with a hip fracture from April 2010 to April 2018. Surgical treatment was performed on the patients of this study. The procedure methods were classified as: total hip arthroplasty, hemiarthroplasty, percutaneous fixation, intramedullary nail fixation and plate/screw fixation. The primary interest of end point of this study is the development of POP during the postoperative period. The postoperative period in this study was defined as the time from 24 hours after surgery to discharge. The diagnostic criteria for pneumonia were set according to the guidelines built by the Infectious Diseases Society of America and the American Thoracic Society (Guidelines for the Management of Adults with Hospital-acquired, Ventilator-associated, and Healthcareassociated Pneumonia, 2005). Potential variables for developing POP were identified using logistic regression analyses initially and were further selected via the method of LASSO. Then the independent risk factors were identified by multivariable regression analyses. A predictive nomogram was built based on the multiple regression model, and the calibration abilities of the nomogram was measured by Harrel C-index, calibration plot and Hosmer-Lemeshow test respectively. Decision curve analysis was carried out to assess the net benefit due to threshold probability and an on-line questionnaire survey was conducted among the clinicians to assess the applicability of the nomogram coherently.

Results: Of the 1285 patients, 70 (5.4\%) developed POP. COPD, number of comorbidities, ASA classification $>2$, preoperative dependent functional status and cognitive impairment were identified as independent risk factors of POP. The nomogram built based on the results showed good accordance between the predicted probabilities and the observed frequency. The decision curve analysis confirmed the clinical utility of the nomogram when the threshold probabilities were between $5 \%$ and $65 \%$ due to the net benefit, while the results of on-line questionnaire among 200 clinicians showed that $91.5 \%$ of the participants had a mental shreshold of intervention between $5-50 \%$.

Conclusion: 1. COPD, number of comorbidities, ASA classification $>2$, preoperative dependent functional status and cognitive impairment were independent risk factors for POP. 2 . The nomogram built in this study has a good accordance between the predictive risk and the observational incidence. The results of decision curve and questionnaire among clinicians show well applicability of the nomogram.

\section{Background}

As a worldwide public health concern, hip fracture has ranked one of the top 10 causes of disability [1] and contributed to high mortalities and morbidities in the elderly population, which leads to increasing socioeconomic cost $[2,3]$. The one-year mortality rate could be as high as $36 \%$ despite progressive surgical management and accelerated rehabilitation [4]. Many life-threatening complications have been 
investigated in current literature, such as cardiac infarction, stroke, deep vein thrombosis and subsequent pulmonary embolism $[5,6]$, while little has been studied regarding pneumonia, a troubling complication following hip fracture surgery [7]. Little is known for the occurrence of postoperative pneumonia (POP) during the hospital stay. The purpose of this study is to determine the incidence and independent risk factors of POP after hip fracture surgeries in geriatric patients, to construct a predictive nomogram for the development of POP and to evaluate the accuracy and clinical applicability of the nomogram.

\section{Patients And Methods}

\section{Patient Population}

In this study, we retrospectively studied 1285 patients with hip fractures and treated by surgical management between April 2010 and April 2018 in a single center. The inclusion criteria of patients are as follows: 1 ) age $\geq 65,2$ ) postoperative diagnosis of unilateral femoral neck fracture, or intertrochanteric fracture; 3 ) receiving total hip arthroplasty, or hemiarthroplasty, or percutaneous fixation, intramedullary nail fixation, or plate/screw fixation. The exclusion criteria included: 1) pathological fractures or history of diagnostic malignant tumor, 2) multiple injuries, 3) open fractures.

Patients were characterized at baseline according to sex, age, body mass index (BMI), comorbidities, current smoking status, fracture pattern, risk classification of anesthesia according to American Association of Anesthesiologists (ASA), type of anesthesia, surgery option, time to surgery, operation time, blood loss, transfusion, preoperative hemoglobin and serum albumin concentration, intensive care, and length of hospital stay, etc. (Table 1).. Age was stratified into $65-74,70-74,75-79,80-84$, and $\geq 85$ years. Hemoglobin was stratified into $<120 \mathrm{~g} / \mathrm{L}$ in male and $<110 \mathrm{~g} / \mathrm{L}$ in female (anemia) versus $\geq 120 \mathrm{~g} / \mathrm{L}$ in male and $\geq 110 \mathrm{~g} / \mathrm{L}$ in female (normal). Serum albumin was stratified into $<35 \mathrm{~g} / \mathrm{L}$ (hypoalbuminemia) versus $\geq 35 \mathrm{~g} / \mathrm{L}$ (normal). Transfusion was stratified into $>2$ units of RBC or not. Time to surgery, which was calculated in days, was defined as the time elapsed from hospital admission to surgery [8]. Surgery procedure was stratified as described above.

Patients were characterized according to whether or not they developed pneumonia in the postoperative period. The postoperative period in this study was defined as the time from 24 hours after surgery to discharge. The diagnostic criteria for pneumonia were set according to the guidelines built by the Infectious Diseases Society of America and the American Thoracic Society (Guidelines for the Management of Adults with Hospital-acquired, Ventilator-associated, and Healthcare-associated Pneumonia, 2005) [9]. In the guidelines, pneumonia was defined as the presence of "new lung infiltrate plus clinical evidence that the infiltrate is of an infectious origin, which includes the new onset of fever, purulent sputum, leukocytosis, and decline in oxygenation." Accordingly, in our study, the identification of development of pneumonia should accord with the following events that could be confirmed in the patients' medical/nursing records and radiological database: 1) a radiographic (X-ray or CT scan) infiltrate that is new or progressive, 2) observable clinical symptoms, which included a new onset of fever with a axillary temperature over $37.0^{\circ} \mathrm{C}$, and/or purulent sputum with a positive sputum culture, 3) 
leukocytosis. Two experienced doctors (the co-first authors of this study) independently identified the diagnosis of POP for all patients following the diagnostic strategies. Any controversies in diagnosis between the two doctors were settled by discussion, and a final diagnosis for POP on each patient was made.

\section{Statistical Analysis}

The primary end point of interest in this study was the development of POP. Multivariable regression analysis was conducted by logistic regression model, and this model was the basis of the POP prediction model. The potential predictors of POP analyzed in this study included age, sex, body mass index, smoking status, hypertension, diabetes, COPD, congestive heart failure, preoperative functional status, fracture pattern, ASA classification, serum albumin, hemoglobin, time to surgery, anaesthesia type, operation type, operation time, blood loss, transfusion, and ICU stay. An initial univariate logistic regression model was fitted to evaluate the association between the clinical factors and pneumonia. To identify independent risk factors, variables achieving a significance level of $p<0.05$ were initially selected out. The method of LASSO was used to select potential strong factors and then independent predictors were identified by multiple regression analysis. The independent statistically significant predictors in the final model were determined with the backward method based on the AIC criteria. A predictive nomogram was established based on results of the multiple regression. A predictive discrimination was evaluated using Harrel Concordance index (C-index), which measured the probability that, given a pair of randomly selected patients, the model correctly predicted which patient will experience an event first. The C-index of the model can range between 0.5 , which represents random chance, and 1.0 , which represents a perfectly discriminating model (Harrell et al, 1982). The relatively correctional C-index of the nomogram was calculated by bootstraps with 1000 resamples. In calibration, the predicted probability of postoperative pneumonia generated by 10 -fold cross validation was compared with the observed cumulative incidence estimates of pneumonia probability. The consistency of the curves was evaluated by Hosmer-Lemeshow $(\mathrm{H}-\mathrm{L})$ test. All statistical analyses were conducted using R software version 3.5.0 (http://www.rproject.org/), with rms package (Harrell, 2012).In addition, the decision curve analysis was carried out using the code found at https://www.mskcc.org/departments/epidemiology biostatistics/ healthoutcomes/decision-curve-analysis-01 according to its tutorials, and an on-line questionnaire (Appendix. 1) was conducted on Tencent Questionnaire Platform from February 11, 2019 to February 15, 2019 combined with the decision curve to study the threshold for intervention among clinical practitioners, which was used to evaluate the clinical applicability of the nomogram comprehensively.

\section{Results}

\section{Baseline characteristics}

There were 1409 patients who met the inclusion criteria for this study, of which 124 were excluded due to the exclusion criteria. Finally, 1285 patients were included in this study. The clinical and pathologic 
characteristics of patients were listed in Table 1. There were 389 (30.3\%) male and $896(69.7 \%)$ female patients in total with a median age of 80 (IQR, 75-84 years) at the time of diagnosis. 770 patients $(59.9 \%)$ had comorbidities preoperatively. 334 patients $(26.0 \%)$ had two or more than two kinds of comorbidities. Hypertension (43.5\%) and diabetes (16.4\%) were the most common comorbidities. COPD (3.8\%) and congestive heart failure (2.8\%) also constituted a small amount of comorbidities. Eventually, $70(5.4 \%)$ patients developed POP, of which 30 (42.9\%) were male and $40(57.1 \%)$ were female.

\section{Comparison of the clinicopathological features between patients with and without POP}

Patients were characterized according to whether or not they developed pneumonia in the postoperative period. The postoperative period in this study was defined as the time from 24 hours after surgery to discharge. So the observation period of this study was limited to the duration of hospitalization.

Compared to patients without POP, those with POP had more older age individuals ( 82 vs. $79, p=0.001$ ), a higher portion of male sex (42.9\% vs. $29.5 \%, p=0.026)$, a higher portion of patients who had an ASA classification higher than grade $2(52.6 \%$ vs. $25.0 \%, p=0.017)$, more individuals who had at least two kinds of comorbidities ( $72.9 \%$ vs. $23.3 \%$, p $<0.001)$, more dependent functional status $(47.1 \%$ vs. $21.3 \%$, $\mathrm{p} \rrbracket$ $0.001)$ and more preoperative hypoproteinemia $(55.7 \%$ vs. $36.1 \%, p=0.002)$, a higher rate of diabetes ( $28.6 \%$ vs. $15.7 \%, p=0.008)$, more COPD ( $28.6 \%$ vs. $2.39 \%, p<0.001)$, more congestive heart failure $(30.0 \%$ vs. $1.23 \%, \mathrm{p}<0.001)$, postoperative ICU stay ( $36.8 \%$ vs. $15.7 \%, \mathrm{p} \nabla 0.001)$ and more postoperative delirium (24.3\% vs. $13.8 \%, p=0.025)$. (Table 1$)$.

\section{Multiple regression analysis}

The results of the univariate regression analysis were shown in Table 2. In the univariate logistic regression, male sex $(p=0.022)$, age $(p=0.002)$, preoperative cognitive impairment $(p<0.001)$, number of comorbidities $\geq 2(p<0.001)$, diabetes $(p=0.009)$, COPD $(p<0.001)$, ASA classification $>2(p<0.001)$, preoperative hypoproteinemia $(p=0.001)$, preoperative dependent functional status $(p<0.001)$ and postoperative ICU stay $(p=0.006)$ were found to be significant predictors of POP. These factors were further filtrated by the method of LASSO. Comparatively weaker factors were eliminated so that the strength of influence of the factors was enhanced. Finally, in multiple regression analysis, COPD, number of comorbidities, ASA classification $>2$, preoperative dependent functional status and cognitive impairment were identified as independent risk factors of POP. (Table 3)..

\section{Development of a predictive nomogram and utility of the nomogram}


To provide the physicians with a quantitative method to predict the risk of postoperative pneumonia, we constructed a predictive nomogram (Figure 1) according to the strength of influence of each independent risk factors based on the multivariable logistic regression (Table 3)..

To use the nomogram, a vertical line was drawn up to the top point row to assign points for each variable. Then, the total number of points was calculated, and a vertical line was drawn downwards from the total point row to obtain the probability of POP. The risk of POP increased with the increasing total points, due to the nomogram. The total points of the nomogram ranges from 0 to 35 points, corresponding to the predicted risk of POP from less than $10 \%$ to greater than $85 \%$. (Figure 1).. For example, when the total points was calculated to be 15 , the corresponding risk of postoperative pneumonia was $20 \%$.

\section{Validation of the nomogram}

The nomogram was validated by the method of Harrel C-index and a calibration plot using the R software 3.0. $\mathrm{H}-\mathrm{L}$ test was performed to evaluate the statistical significance of the consistency between the curves in the calibration plot.

The nomogram displayed a C-index of $0.84(95 \% \mathrm{Cl} 0.78-0.90)$ which indicated good accuracy of the predictive model. The calibration plot showed good concordance between predicted probability and actual probability. (Figure. 2).. The H-L test showed that the curves in the calibration plot had statistical significance. $(p=0.88)$

Based on the threshold probability, the decision analysis curve was leveraged to evaluate the clinical application of a prediction model. In the decision analysis curve, the nomogram is compared with the null model for its added value, which turned out that the nomogram was applicable when thresholds were in the range of 0.05 to 0.65 due to the net benefit (Figure. 3)..

The results of on-line questionnaire among 200 clinicians showed that $89.5 \%$ of the participants have obtained Identification of Physician's Qualification for more than 5 years. $52.5 \%$ had senior professional qualifications. $88.5 \%$ have been working as an orthopedist for more than 5 years. $62 \%$ had an experience of surgical treatment for geriatric hip fractures for more than 100 cases. $97 \%$ of the participants declared that they had encountered POP among geriatric hip fracture patients in their career. $91.5 \%$ had a threshold of intervention when predictive risk of POP ranged from $5 \%$ to $50 \%$, which slickly conformed to the net-benefit threshold interval produced by the decision curve, indicating well clinical applicability of the nomogram.

\section{Discussion}

The increasing number of hip fractures worldwide predicts greater impact to health status in elderly population. In the United States, it has been estimated that the total number of hip fractures might double by the year 2040 compared to the 1980s [2]. Greater contributions should be made by Asian countries for 
the increasing number of osteoporotic hip fractures in future decades [10]. The risk of mortality and morbidity within one year of fracture remains high according to the existing literatures $[4,11 \sim 14]$.

The improvements in surgical and rehabilitation managements these years have improved clinical outcomes of hip fractures, while complications following hip fracture surgery remain frequent and troubling and are often complex, which might be caused by various factors, such as general conditions, comorbidities, traumatic impairment, surgery, anesthesia, and immobilization, etc. Several studies have focused on the fatal adverse events during the postoperative periods, such as acute myocardial infarction, stroke, deep vein thrombosis, etc. [16 20], which were known as the most dangerous events.

Pneumonia is also known to be a devastating complication after hip fracture surgery, which can also be life-threatening when correlative respiratory and circulatory failure was induced subsequently, and is especially risky to elderly patients who are more easily affected by the impactions of trauma and immobilization after fractures and surgeries. The reported incidence of pneumonia in elderly patients with a hip fracture was $1.2 \%$ preoperatively [22] and approximately $4 \% \sim 5 \%$ postoperatively according to recent literatures $[14,15,21]$. Although the overall incidence was not alarmingly great, it was found that patients who developed pneumonia would have a higher readmission rate, a higher rate of sepsis, and a higher mortality rate [15]. In our study, 70 (5.4\%) of 1285 patients developed postoperative pneumonia, which involved the time from 24 hours after surgery to discharge. The latest guidelines built by the Infectious Diseases Society of America and the American Thoracic Society in 2016 [23] has differed Ventilator Associated Pneumonia (VAP) from the traditional concept of Hospital Associated Pneumonia (HAP). However, in developing countries, such as China, situation remains different. Community mechanical ventilator equipment is far from popularized yet, so ventilators still could only be seen in the intensive care unit in hospital in most cases. The development of POP will significantly increase the length of stay, while clinical data would be hard to collect after discharge. Therefore, in this study, we defined POP as a new-onset pneumonia from 24 hours after surgery to discharge, so that all the clinical and radiological evidences could be exactly obtained.

Little was known regarding the occurrence of pneumonia in postoperative periods. In a recent retrospective study of 29, 377 patients, male sex, older age, low body-mass index (BMI), and chronic obstructive pulmonary disease (COPD) were identified to be the strongest risk factors for pneumonia [15]. Our study has also shown that COPD, ASA classification, number of comorbidities, cognitive impairment and preoperative dependent functional status were identified to be the independent risk factors for the development of POP. We considered that the smaller sample and ethnological difference might play a role in the discrepancy of the results.

The impacts of pneumonia on clinical outcomes and rehabilitations in elderly patients with a hip fracture has been demonstrated, and it has been suggested that prevention of pneumonia is necessary to improve the outcome of hip fracture [15]. In a recent research,a nonrandomized, Quasi-experimental study was designed to evaluate an inpatient pulmonary rehabilitation program by comparing 2 sequential time periods in a same center [24], and a pulmonary rehabilitation program was demonstrated to be effective 
to reduce the incidence of pneumonia. For elderly patients, prevention for complications is more important than that for cure. Thus, an effective prediction strategy is urgently needed clinically. However, previous researches have many limitations regarding the prediction strategies for POP, and prospective studies were rarely found in current literature.

The main advantages of this study include: first, a nomogram was built for the prediction for the development of POP, with good accuracy according to the statistical verifications. As a graphical presentation of predictive model, nomogram has been widely used in the area of oncology [25-28], with great advantages such as easy operation, convenience and effectiveness. Previously, we have reported the predictive nomogram for the development of postoperative delirium in elderly patients with a hip fracture [29]. The nomogram created in this study is supposed to be used clinically as a prediction method in the preoperative assessment, thus further studies with prospective designs can be conducted based on the existing preliminary results. Second, we evaluated the clinical applicability of the nomogram through the method of decision curve analysis combining with the questionnaire of clinical practitioners. The decision curve showed that the nomogram was applicable when thresholds were in the range of 0.05 to 0.65 due to the net benefit compared with the null model for its added value, while the results of questionnaire showed $91.5 \%$ of the clinicians had a threshold of intervention when predictive risk of POP ranged from $5 \%$ to $50 \%$, which slickly conformed to the net-benefit threshold interval produced by the decision curve. It gives the presentation of the clinical utility of a predictive model more intuitively, making up for the deficiency of the traditional receiver operator characteristic curve.

The main limitations of this study include the following: firstly, it was a retrospective study, so the level of evidence was limited; secondly, it was programmed in a single institution, thus the sample size was small when compared to multi-center studies, and the selection of medical institution by patients might cause potential bias. Then, as the definition of the primary end point of this study-POP, the observation period of this study was limited to the duration of hospitalization, so the follow-up time was short.

\section{Conclusion}

This study showed that COPD, number of comorbidities, ASA classification $>2$, preoperative dependent functional status and cognitive impairment were independent risk factors of POP. The predictive nomogram established in this study showed a good accuracy in predicting the risk of POP and was applicable for clinical practice.

\section{Abbreviations}

POP:postoperative pneumonia, BMI:body mass index, ASA:American Association of Anesthesiologists, COPD:chronic obstructive pulmonary diseases.

\section{Declarations}




\section{Authors' contributions}

Dr. Da-ke Tong and Dr. Fang Ji conceived and designed this research. Data collection and extraction was performed by Dr. Xin Zhang and Dr. Xu-zhou Duan.Data was verifed by Dr.Kai-hang Xu and Dr.Rong-zhi He. Statistical analysis was performed by Dr. Xin Zhang and Dr. Xu-zhou Duan participated in drafting article. All authors gave fnal approval to the version submitted. All authors approved the fnal manuscript.

\section{Acknowledgements}

The authors of this research wish to thank the departments of Orthopedics and Record Room, Changhai Hospital affiliated to Second Military Medical University.

\section{Funding}

No Funding.

\section{Availability of data and materials}

Data associated with this study are retained at a central repository at the Orthopaedic Department, Changhai Hospital affiliated to Second Military Medical University. If there are any questions, please contact the corresponding author.

\section{Ethics approval and consent to participate}

Not applicable.

\section{Consent for publication}

Not applicable.

\section{Competing interests}

The authors declare that they have no competing interests.

\section{References}

1. zMarks R. Hip fracture epidemiological trends, outcomes, and risk factors, 1970-2009. Int J Gen Med.2010, (3):1-17

2. Cummings SR, Rubin SM, Black D. The future of hip fractures in the United States: numbers, costs, and potential effects of postmenopausal estrogen. Clin Orthop Relat Res 1990; 252: 163-6

3. Swart E; Vasudeva E; Makhni EC; Macaulay W; Bozic KJ. Dedicated Perioperative Hip Fracture Comanagement Programs are Cost-effective in High-volume Centers: An Economic Analysis. Clin Orthop Relat Res. 2016 Jan; 474(1):222-33 
4. Bhandari M, Devereaux PJ, Swiontkowski MF, et al. Internal fixation compared with arthroplasty for displaced fractures of the femoral neck: a meta-analysis. J Bone Joint Surg Am 2003; 85-A: 1673-81.

5. Sathiyakumar V; Avilucea FR; Whiting PS; Jahangir AA; Mir HR; Obremskey WT et al. Risk factors for adverse cardiac events in hip fracture patients: an analysis of NSQIP data. Int Orthop. 2016 Mar; 40(3):439-45

6. Sathiyakumar V; Greenberg SE; Jahangir AA; Mir HH; Obremskey WT; Sethi MK. Impact of type of surgery on deep venous thrombi and pulmonary emboli: a look at twenty seven thousand hip fracture patients. Int Orthop. 2015 Oct; 39(10):2017-22

7. Lv H; Yin P; Long A; Gao Y; Zhao Z; Li J et al. Clinical characteristics and risk factors of postoperative pneumonia after hip fracture surgery: a prospective cohort study. Osteoporos Int. 2016 Oct; 27(10):3001-9 PMID: 27241669. doi:

8. Daniel Pincus, Bheeshma Ravi, David Wasserstein, Anjie Huang, J. Michael Paterson, Avery B. Nathens, Hans J. Kreder, Richard J. Jenkinson, Walter P. Wodchis. Association between wait time and 30-day mortality in adults undergoing hip fracture surgery. J A M A, 2017; 318(20): 1994-2003

9. American Thoracic Society (ATS) and Infectious Diseases Society of America (IDSA). Guidelines for the management of adults with hospital-acquired, ventilator-associated, and healthcare-associated pneumonia. Am J Respir Crit Care Med 2005; 171:388-416.

10. Dhanwal DK, Dennison EM, Harvey NC, Cooper C. Epidemiology of hip fracture: worldwide geographic variation. Indian J Orthop 2011; 45: 15-22

11. Zuckerman JD. Hip fracture. New England journal of medicine. 1996; 240 334(23):1519-1525.

12. Sathiyakumar V, Greenberg SE, Molina CS, Thakore RV, Obremskey WT, Sethi MK. Hip fractures are risky business: an analysis of the NSQIP data. Injury. 2015; 46(4):703-8

13. Donegan DJ, Gay AN, Baldwin K, Morales EE, Esterhai JL Jr, Mehta S. Use of medical comorbidities to predict complications after hip fracture surgery in the elderly. J Bone Joint Surg Am. 2010 Apr; 92(4):807-13

14. Vidán M, Serra JA, Moreno C, Riquelme G, Orti:i J. Efficacy of a comprehensive geriatric intervention in older patients hospitalized for hip fracture: a randomized, controlled trial, J Am Geriatr Soc. 2005:53:1476-82

15. Bohl Daniel D, Sershon Robert A, Saltzman Bryan M, Darrith Brian, Della Valle, Craig J. Incidence, risk factors, and clinical implications of pneumonia after surgery for geriatric hip fracture. J Arthroplasty. 2018; 33(5): 1552-6.e1

16. Pedersen, Alma B; Ehrenstein, Vera; Szépligeti, Szimonetta K; Sørensen, Henrik T. Hip fracture, comorbidity, and the risk of myocardial infarction and stroke: a Danish nationwide cohort study, 1995-2015. J Bone Miner Res.2017V32N12:2339-2346

17. Huddleston JM, Gullerud RE, Smither F et al. Myocardial infarction after hip fracture repair: A population-based study. J Am Geriatr Soc 2012; 60: 2020-2026.

18. Carnevale Vincenzo, Fontana Andrea, Scillitani Alfredo, Sinisi Roberto, Romagnoli Elisabetta, Copetti Massimiliano. Incidence and all-cause mortality for hip fracture in comparison to stroke, and 
myocardial infarction, a fifteen years population-based longitudinal study. Endocrine 2017, 58(2): 320-331

19. Durand, WM; Goodman, AD; Johnson, JP; Daniels, AH. Assessment of 30-day mortality and complication rates associated with extended deep vein thrombosis prophylaxis following hip fracture surgery. Injury 2018, 49(6): 1141-1148

20. Zhang Bin-Fei, Wei Xing, Huang Hai, Wang Peng-Fei, Liu Ping, Qu Shuang-Wei, Li Jia-Hao, Wang $\mathrm{Hu}$, Cong Yu-Xuan, Zhuang Yan, Zhang Kun. Deep vein thrombosis in bilateral lower extremities after hip fracture, a retrospective study of 463 patients. Clin Interv Aging, 2018.

21. Lv H, Yin P, Long A, Gao Y, Zhao Z, Li J, Zhang L, Zhang L, Tang P. Clinical characteristics and risk factors of postoperative pneumonia after hip fracture surgery, a prospective cohort study. Osteoporos Int.2016, 27(10):3001-9

22. Patterson Joseph T, Bohl Daniel D, Basques Bryce A, Arzeno Alexander H, Grauer Jonathan N. Does Preoperative Pneumonia Affect Complications of Geriatric Hip Fracture Surgery? Am J Orthop (Belle Mead NJ).2017, 46(3): E177-E185

23. Kalil AC, Metersky ML, Klompas M, Muscedere J, Sweeney DA, Palmer LB, Napolitano LM, O'Grady NP, Bartlett JG, Carratalà J, El Solh AA, Ewig S, Fey PD, File TM, Restrepo MI, Roberts JA, Waterer GW, Cruse P, Knight SL, Brozek JL. Management of Adults With Hospital-acquired and Ventilatorassociated Pneumonia: 2016 Clinical Practice Guidelines by the Infectious Diseases Society of America and the American Thoracic Society. Clin Infect Dis. 2016, 63(5): e61-111

24. Chang Shih-Chieh, Lai Jiun-I, Lu Mei-Chin, Lin Kuan-Hung, Wang Wei-Shu, Lo Su-Shun, Lai Yi-Chun. Reduction in the incidence of pneumonia in elderly patients after hip fracture surgery, an inpatient pulmonary rehabilitation program. Medicine 2018, 97(33): e11845

25. Graesslin O, Abdulkarim BS, Coutant C, Huguet F, Gabos Z, Hsu L, Marpeau O, Uzan S, Pusztai L, Strom EA, Hortobagyi GN, Rouzier R, Ibrahim NK. Nomogram to predict subsequent brain metastasis in patients with metastatic breast cancer. : 2032-7

26. Tsoutsou Pelagia G, Jeanneret Sozzi Wendy, Matzinger Oscar, Ozsahin Mahmut. Nomograms predicting locoregional recurrence in the subtype era of breast cancer. J Clin Oncol. 2013, 31(5): 647648

27. Li J, Liu Y, Yan Z, Wan, X, Xia Y, Wang K, Liu J, Lau W Y, Wu M, Shen, F. A nomogram predicting pulmonary metastasis of hepatocellular carcinoma following partial hepatectomy. Br J Cancer. 2014, 110(5): 1110-1117

28. Semenkovich TR, Yan Y, Subramanian M, Meyers BF, Kozower BD, Nava R, Patterson GA, Kreisel D, Puri V. A clinical nomogram for predicting node-positive disease in esophageal cancer. Ann Surg, 2019(3): doi 10.1097/SLA.0000000000003450

29. Zhang Xin, Tong Da-Ke, Ji Fang, Duan Xu-Zhou, Liu Pei-Zhao, Qin Sheng, Xu Kai-Hang, Di-Li Xia-Ti. Predictive nomogram for postoperative delirium in elderly patients with a hip fracture. Injury, 2019, 50(2): 392-397 


\section{Tables}

Table 1. Baseline Characteristics of patients 


\begin{tabular}{|c|c|c|c|c|}
\hline & ALL & No & Yes & $\mathbf{p}$ \\
\hline & $\mathrm{N}=1285$ & $\mathrm{~N}=1215$ & $\mathrm{~N}=70$ & \\
\hline Gender: & & & & 0.026 \\
\hline female & $896(69.7 \%)$ & $856(70.5 \%)$ & $40(57.1 \%)$ & \\
\hline male & $389(30.3 \%)$ & $359(29.5 \%)$ & $30(42.9 \%)$ & \\
\hline Age, years & $80.0(75.0-84.0)$ & $79.0(75.0-84.0)$ & $82.0(79.0-86.8)$ & 0.001 \\
\hline Age, years: & & & & 0.014 \\
\hline $65-69$ & $130(10.1 \%)$ & $127(10.5 \%)$ & $3(4.29 \%)$ & \\
\hline $70-74$ & $176(13.7 \%)$ & $170(14.0 \%)$ & $6(8.57 \%)$ & \\
\hline 75-79 & $329(25.6 \%)$ & $317(26.1 \%)$ & $12(17.1 \%)$ & \\
\hline $80-84$ & $330(25.7 \%)$ & $308(25.3 \%)$ & $22(31.4 \%)$ & \\
\hline$\geq 85$ & $320(24.9 \%)$ & $293(24.1 \%)$ & $27(38.6 \%)$ & \\
\hline $\mathrm{BMI} \mathrm{Kg} / \mathrm{m}^{2}$ & $23.4(21.1-25.6)$ & $23.4(21.1-25.6)$ & $23.4(21.5-26.0)$ & 0.326 \\
\hline $\mathrm{BMI} \mathrm{Kgg} / \mathrm{m}^{2}$ : & & & & 0.021 \\
\hline $\mathrm{BMI} \leq 18.5$ & $53(4.12 \%)$ & 48 (3.95\%) & $5(7.14 \%)$ & \\
\hline $18.5<\mathrm{BMI} \leq 20.0$ & $147(11.4 \%)$ & $143(11.8 \%)$ & $4(5.71 \%)$ & \\
\hline $20.0<\mathrm{BMI} \leq 25.0$ & $703(54.7 \%)$ & $664(54.7 \%)$ & $39(55.7 \%)$ & \\
\hline $25.0<\mathrm{BMI} \leq 30.0$ & $335(26.1 \%)$ & $320(26.3 \%)$ & $15(21.4 \%)$ & \\
\hline $\mathrm{BMI}>\mathbf{3 0 . 0}$ & $47(3.66 \%)$ & $40(3.29 \%)$ & $7(10.0 \%)$ & \\
\hline Type of fracture: & & & & 0.136 \\
\hline femoral neck fracture & $706(54.9 \%)$ & $661(54.4 \%)$ & $45(64.3 \%)$ & \\
\hline Intertrochanteric fracture & $579(45.1 \%)$ & $554(45.6 \%)$ & $25(35.7 \%)$ & \\
\hline Cognitive impairment: & & & & $<0.001$ \\
\hline no & $1239(96.4 \%)$ & $1180(97.1 \%)$ & 59 (84.3\%) & \\
\hline yes & $46(3.58 \%)$ & 35 (2.88\%) & $11(15.7 \%)$ & \\
\hline Smoking: & & & & 0.582 \\
\hline never & $984(76.6 \%)$ & $928(76.4 \%)$ & $56(80.0 \%)$ & \\
\hline current/former & 301 (23.4\%) & 287 (23.6\%) & $14(20.0 \%)$ & \\
\hline Comorbidities: & & & & $<0.001$ \\
\hline
\end{tabular}




\begin{tabular}{|c|c|c|c|c|}
\hline no & $515(40.1 \%)$ & $508(41.8 \%)$ & $7(10.0 \%)$ & \\
\hline yes & $770(59.9 \%)$ & $707(58.2 \%)$ & $63(90.0 \%)$ & \\
\hline Comorbidities: & & & & $<0.001$ \\
\hline$<2$ & $951(74.0 \%)$ & $932(76.7 \%)$ & $19(27.1 \%)$ & \\
\hline$\geq 2$ & $334(26.0 \%)$ & $283(23.3 \%)$ & $51(72.9 \%)$ & \\
\hline Hypertension: & & & & 0.99 \\
\hline no & $726(56.5 \%)$ & $687(56.5 \%)$ & 39 (55.7\%) & \\
\hline yes & $559(43.5 \%)$ & $528(43.5 \%)$ & $31(44.3 \%)$ & \\
\hline Diabetes mellitus: & & & & 0.008 \\
\hline no & $1074(83.6 \%)$ & $1024(84.3 \%)$ & $50(71.4 \%)$ & \\
\hline yes & $211(16.4 \%)$ & $191(15.7 \%)$ & $20(28.6 \%)$ & \\
\hline COPD: & & & & $<0.001$ \\
\hline no & $1236(96.2 \%)$ & $1186(97.6 \%)$ & $50(71.4 \%)$ & \\
\hline yes & $49(3.81 \%)$ & $29(2.39 \%)$ & $20(28.6 \%)$ & \\
\hline Congestive heart failure: & & & & $<0.001$ \\
\hline no & $1249(97.2 \%)$ & $1200(98.8 \%)$ & $49(70.0 \%)$ & \\
\hline yes & $36(2.80 \%)$ & $15(1.23 \%)$ & $21(30.0 \%)$ & \\
\hline History of depression: & & & & 1 \\
\hline no & $1279(99.5 \%)$ & 1209 (99.5\%) & $70(100 \%)$ & \\
\hline yes & $6(0.47 \%)$ & $6(0.49 \%)$ & $0(0.00 \%)$ & \\
\hline hypotensive drugs: & & & & 0.99 \\
\hline no & $726(56.5 \%)$ & $687(56.5 \%)$ & 39 (55.7\%) & \\
\hline yes & $559(43.5 \%)$ & $528(43.5 \%)$ & $31(44.3 \%)$ & \\
\hline Hypoglycemic drugs: & & & & 0.171 \\
\hline no & $1184(92.1 \%)$ & $1123(92.4 \%)$ & $61(87.1 \%)$ & \\
\hline yes & $101(7.86 \%)$ & $92(7.57 \%)$ & $9(12.9 \%)$ & \\
\hline Cardiovascular drugs: & & & & 0.001 \\
\hline no & 1189 (92.5\%) & $1132(93.2 \%)$ & $57(81.4 \%)$ & \\
\hline yes & 96 (7.47\%) & 83 (6.83\%) & 13 (18.6\%) & \\
\hline
\end{tabular}


Respiratory drugs:

no

yes

Other drugs:

no

yes

Traction:

no

yes

ASA classification

ASA(2):

1-2

3-4

Pre-operative RBC

Pre-operative WBC

Pre-operative ALB

Pre-operative ALB:

$\geq 35$
$<35$

Pre-operative $\mathrm{Cr}$

Pre-operative HGB

Pre-operative PLT

Time to surgery

Anaesthesia type:

Intra-spinal/nerve block

general

Operation time

Type of operation:

hemiarthroplasty

$\begin{array}{lll}1267(98.6 \%) & 1204(99.1 \%) & 63(90.0 \%) \\ 18(1.40 \%) & 11(0.91 \%) & 7(10.0 \%)\end{array}$

0.025

$1218(94.8 \%) \quad 1156(95.1 \%) \quad 62(88.6 \%)$

$67(5.21 \%)$

$59(4.86 \%)$

$8(11.4 \%)$

0.648

$1184(92.1 \%) \quad 1121(92.3 \%) \quad 63(90.0 \%)$

$101(7.86 \%)$

$94(7.74 \%)$

$7(10.0 \%)$

$2.00(2.00-3.00) \quad 2.00(2.00-3.00) \quad 3.00(2.00-3.00) \quad<0.001$ $<0.001$

$\begin{array}{lll}915(71.2 \%) & 888(73.1 \%) & 27(38.6 \%) \\ 370(28.8 \%) & 327(26.9 \%) & 43(61.4 \%)\end{array}$

$3.75(3.33-4.18) \quad 3.76(3.33-4.17) \quad 3.66(3.23-4.20) \quad 0.284$

$8.20(6.56-9.60) \quad 8.20(6.56-9.60) \quad 8.21(6.49-9.95) \quad 0.955$ $36.0(33.0-38.0) \quad 36.0(33.0-38.0) \quad 34.0(30.0-37.0) \quad 0.002$

0.002

$807(62.8 \%) \quad 776(63.9 \%) \quad 31(44.3 \%)$

$478(37.2 \%) \quad 439(36.1 \%) \quad 39(55.7 \%)$

$67.0(56.0-82.0) \quad 67.0(56.0-81.5) \quad 70.0(61.0-90.5) \quad 0.085$

$114(102-125) \quad 115(102-125) \quad 112(98.0-124) \quad 0.291$

$173(140-214) \quad 172(140-214) \quad 174(142-214) \quad 0.615$
$4.00(3.00-5.00) \quad 4.00(3.00-5.00) \quad 4.50(3.00-6.00) \quad 0.181$

0.582

$\begin{array}{lll}1068(83.1 \%) & 1012(83.3 \%) & 56(80.0 \%) \\ 217(16.9 \%) & 203(16.7 \%) & 14(20.0 \%)\end{array}$

$80.0(60.0-105) \quad 80.0(60.0-105) \quad 87.5(70.0-105)$

0.087

0.591

347 (27.0\%)

$325(26.7 \%)$

$22(31.4 \%)$ 


\begin{tabular}{|lcccc|}
\hline total hip arthroplasty & $298(23.2 \%)$ & $280(23.0 \%)$ & $18(25.7 \%)$ & \\
\hline intramedullary nail & $456(35.5 \%)$ & $437(36.0 \%)$ & $19(27.1 \%)$ & \\
\hline plate/Screw & $153(11.9 \%)$ & $144(11.9 \%)$ & $9(12.9 \%)$ & \\
\hline multiple screw & $31(2.41 \%)$ & $29(2.39 \%)$ & $2(2.86 \%)$ & \\
\hline Blood loss & $200(100-350)$ & $200(100-350)$ & $200(100-300)$ & 0.264 \\
\hline Preoperative anemia: & & & & 0.407 \\
\hline no & $695(54.1 \%)$ & $661(54.4 \%)$ & $34(48.6 \%)$ & \\
\hline yes & $590(45.9 \%)$ & $554(45.6 \%)$ & $36(51.4 \%)$ & \\
\hline Functional status: & & & & \\
\hline independent & $993(77.3 \%)$ & $956(78.7 \%)$ & $37(52.9 \%)$ & \\
\hline dependent & $292(22.7 \%)$ & $259(21.3 \%)$ & $33(47.1 \%)$ & \\
\hline Transfusion $>$ 2iu RBC: & & & & \\
\hline no & $690(53.7 \%)$ & $653(53.7 \%)$ & $37(52.9 \%)$ & \\
\hline yes & $595(46.3 \%)$ & $562(46.3 \%)$ & $33(47.1 \%)$ & \\
\hline Postoperative ICU: & & & & \\
\hline no & $1066(83.0 \%)$ & $1017(83.7 \%)$ & $49(70.0 \%)$ & \\
\hline yes & $219(17.0 \%)$ & $198(16.3 \%)$ & $21(30.0 \%)$ & \\
\hline Length of stay & $10.0(8.00-12.0)$ & $10.0(8.00-12.0)$ & $11.5(9.00-13.0)$ & 0.006 \\
\hline
\end{tabular}

Table 2. Univariable logistic regression 


\begin{tabular}{|c|c|c|}
\hline Risk factors & OR & p. ratio \\
\hline \multicolumn{3}{|l|}{ Gender: } \\
\hline female & Ref. & Ref. \\
\hline male & $1.79[1.09 ; 2.92]$ & 0.022 \\
\hline Age, years & $1.06[1.02 ; 1.09]$ & 0.002 \\
\hline \multicolumn{3}{|l|}{ Age, years: } \\
\hline $65 \sim 69$ & Ref. & Ref. \\
\hline 70 74 & $1.46[0.36 ; 7.43]$ & 0.604 \\
\hline 75 79 & $1.54[0.47 ; 7.18]$ & 0.498 \\
\hline $80 \sim 84$ & $2.89[0.97 ; 12.87]$ & 0.057 \\
\hline$\geq 85$ & $3.72[1.28 ; 16.42]$ & 0.013 \\
\hline BMIIKg/m² & $1.05[0.98 ; 1.12]$ & 0.196 \\
\hline \multicolumn{3}{|l|}{ BMIIKg/m²: } \\
\hline $\mathrm{BMI} \leq 18.5$ & Ref. & Ref. \\
\hline $18.5<\mathrm{BMI} \leq 20.0$ & $0.27[0.06 ; 1.11]$ & 0.069 \\
\hline $20.0<\mathrm{BMI} \leq 25.0$ & $0.55[0.22 ; 1.68]$ & 0.267 \\
\hline $25.0<\mathrm{BMI} \leq 30.0$ & $0.44[0.16 ; 1.44]$ & 0.163 \\
\hline $\mathrm{BMI}>\mathbf{3 0 . 0}$ & $1.66[0.48 ; 6.17]$ & 0.423 \\
\hline \multicolumn{3}{|l|}{ Type of fracture: } \\
\hline intertrochanteric fracture & Ref. & Ref. \\
\hline femoral neck fracture & $1.50[0.92 ; 2.52]$ & 0.107 \\
\hline \multicolumn{3}{|l|}{ Cognitive impairment: } \\
\hline no & Ref. & Ref. \\
\hline yes & $6.32[2.92 ; 12.77]$ & $<0.001$ \\
\hline \multicolumn{3}{|l|}{ Smoking: } \\
\hline never & Ref. & Ref. \\
\hline current/former & $0.82[0.43 ; 1.45]$ & 0.499 \\
\hline \multicolumn{3}{|l|}{ Comorbidities: } \\
\hline no & Ref. & Ref. \\
\hline
\end{tabular}




\begin{tabular}{|c|c|c|}
\hline yes & $6.33[3.07 ; 15.42]$ & $<0.001$ \\
\hline \multicolumn{3}{|c|}{ Comorbidities: } \\
\hline$<2$ & Ref. & Ref. \\
\hline$\geq 2$ & $8.78[5.18 ; 15.51]$ & $<0.001$ \\
\hline \multicolumn{3}{|c|}{ Hypertension: } \\
\hline no & Ref. & Ref. \\
\hline yes & $1.04[0.63 ; 1.68]$ & 0.889 \\
\hline \multicolumn{3}{|c|}{ Diabetes mellitus: } \\
\hline no & Ref. & Ref. \\
\hline yes & $2.15[1.22 ; 3.65]$ & 0.009 \\
\hline \multicolumn{3}{|l|}{ COPD: } \\
\hline no & Ref. & Ref. \\
\hline yes & $16.28[8.51 ; 30.77]$ & $<0.001$ \\
\hline \multicolumn{3}{|c|}{ Congestive heart failure: } \\
\hline no & Ref. & Ref. \\
\hline yes & $33.85[16.50 ; 71.32]$ & $<0.001$ \\
\hline \multicolumn{3}{|c|}{ Hypotensive drugs: } \\
\hline no & Ref. & Ref. \\
\hline yes & $1.04[0.63 ; 1.68]$ & 0.889 \\
\hline \multicolumn{3}{|c|}{ Hypoglycemic drugs: } \\
\hline no & Ref. & Ref. \\
\hline yes & $1.83[0.82 ; 3.63]$ & 0.133 \\
\hline \multicolumn{3}{|c|}{ Cardiovascular drugs: } \\
\hline no & Ref. & Ref. \\
\hline yes & $3.13[1.58 ; 5.80]$ & 0.002 \\
\hline \multicolumn{3}{|c|}{ Respiratory drugs: } \\
\hline no & Ref. & Ref. \\
\hline yes & $12.19[4.28 ; 32.43]$ & $<0.001$ \\
\hline Other $d$ & & \\
\hline
\end{tabular}




\begin{tabular}{|c|c|c|}
\hline no & Ref. & Ref. \\
\hline yes & $2.56[1.08 ; 5.34]$ & 0.034 \\
\hline \multicolumn{3}{|l|}{ Traction: } \\
\hline no & Ref. & Ref. \\
\hline yes & $1.35[0.55 ; 2.85]$ & 0.486 \\
\hline ASA classification & $2.83[1.93 ; 4.15]$ & $<0.001$ \\
\hline \multicolumn{3}{|l|}{ ASA(2): } \\
\hline $1-2$ & Ref. & Ref. \\
\hline $3-4$ & $4.31[2.63 ; 7.18]$ & $<0.001$ \\
\hline Pre-operative RBC & $0.79[0.55 ; 1.13]$ & 0.198 \\
\hline Pre-operative WBC & $0.99[0.89 ; 1.09]$ & 0.827 \\
\hline Pre-operative ALB & $0.91[0.87 ; 0.95]$ & $<0.001$ \\
\hline \multicolumn{3}{|l|}{ Pre-operative ALB: } \\
\hline$\geq 35$ & Ref. & Ref. \\
\hline$<35$ & $2.22[1.37 ; 3.64]$ & 0.001 \\
\hline Pre-operative $\mathrm{Cr}$ & $1.00[1.00 ; 1.01]$ & 0.922 \\
\hline Pre-operative HGB & $0.99[0.98 ; 1.01]$ & 0.318 \\
\hline Pre-operative PLT & $1.00[1.00 ; 1.00]$ & 0.645 \\
\hline Time to surgery & $1.08[0.97 ; 1.19]$ & 0.165 \\
\hline \multicolumn{3}{|l|}{ Anaesthesia type: } \\
\hline intraspinal/nerve block & Ref. & Ref. \\
\hline general & $1.26[0.66 ; 2.24]$ & 0.471 \\
\hline Operation time & $1.00[1.00 ; 1.01]$ & 0.23 \\
\hline \multicolumn{3}{|l|}{ Type of operation: } \\
\hline hemiarthroplasty & Ref. & Ref. \\
\hline multiple screw & $1.08[0.15 ; 3.98]$ & 0.918 \\
\hline plate/screw & $0.93[0.40 ; 2.03]$ & 0.865 \\
\hline total hip arthroplasty & $0.95[0.49 ; 1.81]$ & 0.88 \\
\hline intramedullary nail & $0.64[0.34 ; 1.21]$ & 0.172 \\
\hline
\end{tabular}




\begin{tabular}{|lll|}
\hline Blood loss & $1.00[1.00 ; 1.00]$ & 0.553 \\
\hline no & & \\
\hline yes & Ref. & Ref. \\
\hline Functional status: & $1.26[0.78 ; 2.05]$ & 0.345 \\
\hline independent & & \\
\hline dependent & Ref. & Ref. \\
\hline Transfusion: & $3.29[2.01 ; 5.37]$ & $<0.001$ \\
\hline no & & \\
\hline yes & Ref. & Ref. \\
\hline Postoperative ICU: & $1.04[0.64 ; 1.68]$ & 0.884 \\
\hline no & & \\
\hline yes & Ref. & Ref. \\
\hline Length of stay & $2.21[1.27 ; 3.72]$ & 0.006 \\
\hline
\end{tabular}

Table 3. Multiple Logistic Regression for risk factors of POP 


\begin{tabular}{|llll|}
\hline Risk factors & OR & 95\%Cl & P value \\
\hline COPD & & & $<0.001$ \\
\hline No & Ref. & & \\
Yes & 10.38 & $4.90-22.00$ & \\
\hline Number of comorbidities & & & $<0.001$ \\
\hline$<2$ & Ref. & & \\
\hline$\geq 2$ & 5.50 & $3.07-9.84$ & \\
\hline ASA classification & & & 0.001 \\
\hline $1-2$ & Ref. & & \\
\hline $3-4$ & 2.92 & $1.68-5.09$ & \\
\hline Preoperative functional status & & & $<0.001$ \\
\hline independent & Ref. & & \\
\hline dependent & 3.33 & $1.90-5.84$ & \\
\hline Cognitive impairment & & & 0.002 \\
\hline no & Ref. & & \\
\hline yes & 4.26 & $1.69-10.70$ & \\
\hline
\end{tabular}

C-index: 0.8396355 (0.7838565-0.8954145)

HL test: $p=0.8839044$

Figures 
Points

Cognitive impairment

Number of comorbidities

ASA classification

COPD

Preoperative functional status

Total Points

Risk of postoperative pneumonia

\section{Figure 1}

Predictive nomogram

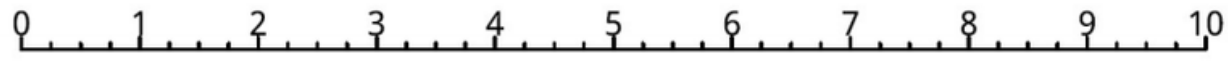

yęs
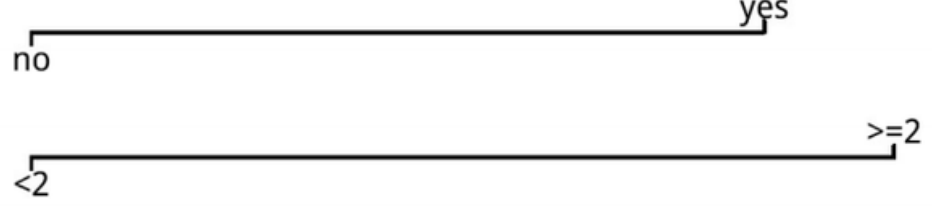

$3-4$

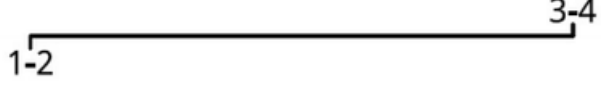

no

yess

dependent

independent

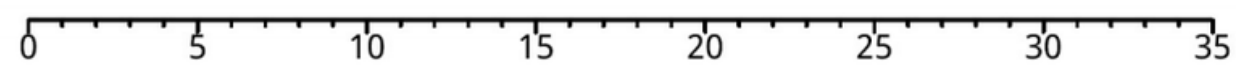

$\begin{array}{lllllllll}0.1 & 0.2 & 0.3 & 0.4 & 0.5 & 0.6 & 0.7 & 0.80 .85\end{array}$ 


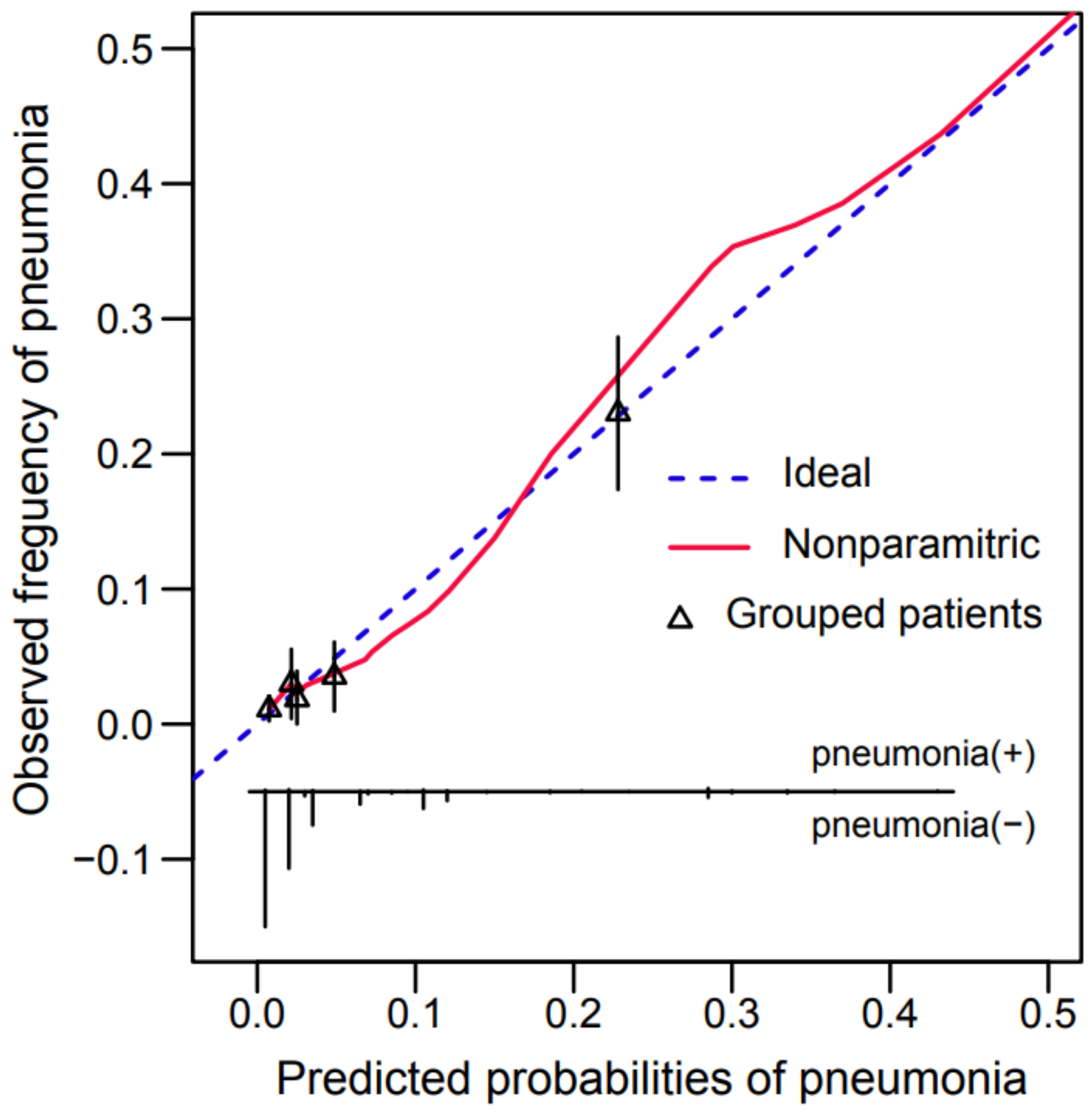

Figure 2

Calibration plot 


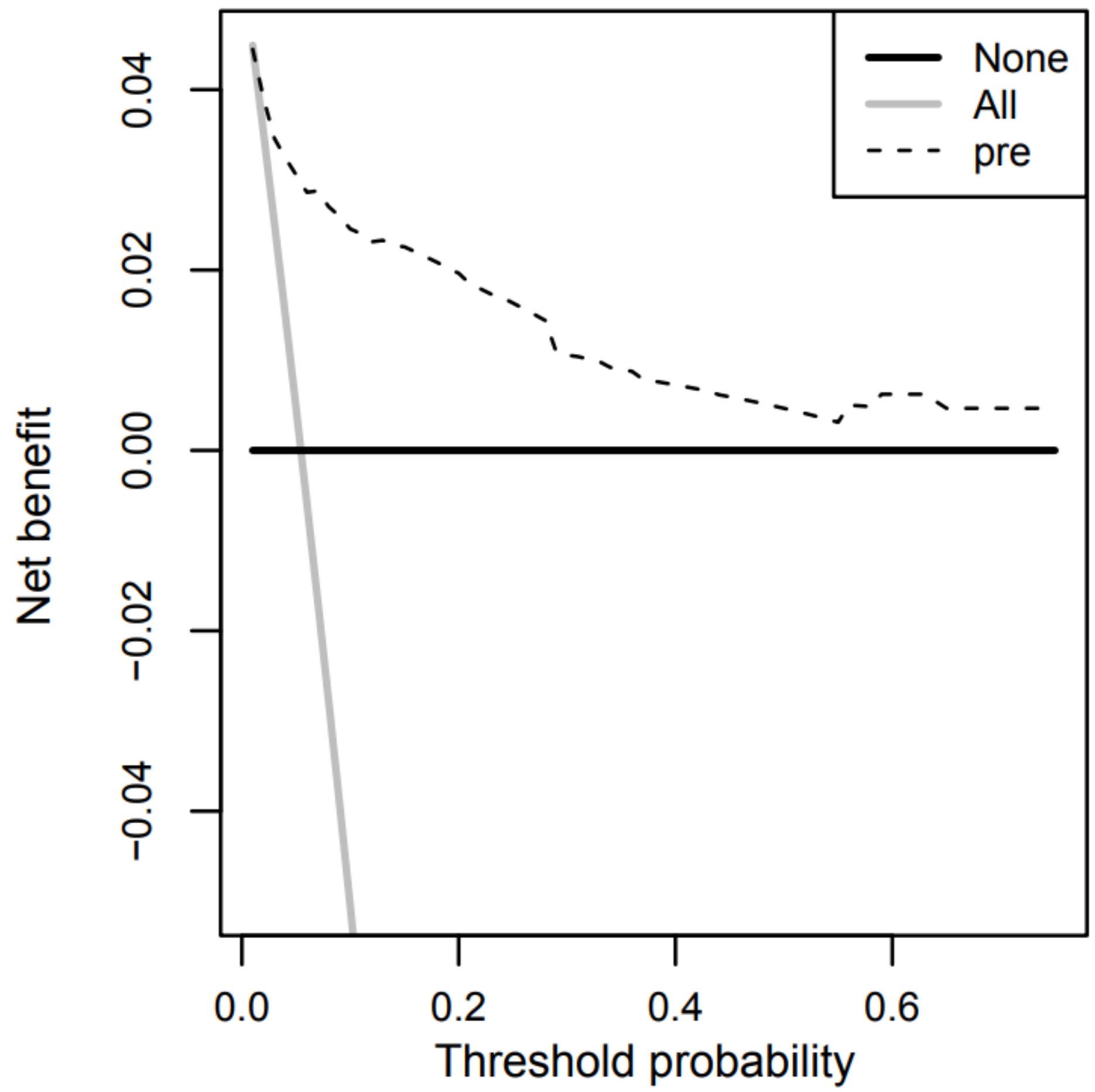

Figure 3

Decision analysis curve

\section{Supplementary Files}

This is a list of supplementary files associated with this preprint. Click to download.

- Supplementaryinformation.docx 
- Appendix1.OnLineQuestionnair.docx

Page 25/25 